\title{
Investigation of the Leg Lymphatic Function in Patients with Leg Acute Venous Thrombosis and in Patients with Leg Post-Thrombotic Syndrome
}

\author{
Andrea Cariati* \\ General Surgery, San Martino Hospital, Genoa, Italy \\ Specialization School of Thoracic Surgery, University of Genoa, Genoa, Italy
}

\begin{abstract}
Lymphatic and venous systems work together to drain interstitial fluid and blood respectively. Data on lymphatic function in chronic venous insufficiency and in chronic venous ulcerations are discordant. Modification of lymphatic function in acute venous thrombosis have been never described. The aim of this study is to report the modifications of the function of the lymphatic system in acute venous thrombosis, chronic venous ulceration and post-thrombotic syndrome.

Material and Methods: Patients were studied with qualitative and semi-quantitative lymphoscintigraphy. The transport index (TI 60) have been calculated for each patients. Data obtained in group a (13 patients with acute venous thrombosis) (TI $60=398)$; group b (12 limbs of 6 controls) (TI $60=203)$; group c (10 limbs with chronic venous ulcerations) (TI $60=$ 114); group d (6 limbs with post-thrombotic syndrome in absence of ulcerations) (TI $60=148$ ) were compared with Kruscall-Wallis statistic and Mann-Whitney test.

Results: The TI 60 is different in the four groups. Differences are significant between: group a (TI $60=398)$ and group b (TI $60=203)$; group b (TI $60=203)$ and group c (TI $60=114)$; group b $($ TI $60=203)$ and group d $($ TI $60=148)$.

Discussion: The compensatory function of lymphatic system in acute venous thrombosis is definitively demonstrated. The lymphatic drainage of the limb affected by chronic venous ulceration is reduced. After the healing of the ulceration the lymphatic flow of the limbs affected by post-thrombotic syndrome improves but it remains under the levels of normal subjects.
\end{abstract}

Keywords: Acute venous thrombosis, lymphoscintigraphy, chronic venous ulceration, post-thrombotic syndrome.

\section{INTRODUCTION}

The blood circulation has been well studied since its discovery by William Harvey [1]. On the contrary, the lymphatic system has mostly been neglected although the lymphatic vessels were discovered by Gaspare Aselli $[2,3]$ and described in his famous book "De Lactibus Sine Lacteis Venis" at the same time. Venous and lymphatic systems work together to drain blood and interstitial fluid, respectively, every second of our life.

In chronic venous insufficiency, increased intralymphatic pressure and dilatation of the lymphatics accompany increased venous pressure [4-6]. Isotope lymphography, in patients with lower extremities edema of venous origin, revealed, in one study, an increase of the lymphatic flow [7]. Lymphoscintigraphy in patients with chronic venous ulceration showed a reduction of the lymph flow $[8,9]$. Incomplete filling of dermal lymphatics has been seen adjacent to venous ulcers by direct contrast lymphography [10].

Venous disease is the most common cause of leg ulcer. Varicous veins are present in nearly the $30 \%$ of the female and in nearly the $15 \%$ of the male adult [11-17]. Venous

*Address correspondence to this author at the Via Fratelli Coda 67/5 A, 16166-Genoa, Italy; Tel: +39-010-3724909;

E-mail: andrea.cariati@libero.it ulcers occur in nearly the $0.3 \%$ of adult population in Western countries $[13,18]$. The prevalence of active and healed ulcers, combined, is nearly $1 \%[19,20]$. The overall prognosis of venous ulcers is poor: the $20 \%$ remain open at two years and the $8 \%$ at five years [21]. The annual cost of venous ulcers has been estimated to be superior to 1 billion US dollars in United States of America [22] and the cost of chronic venous insufficiency to the society is estimated to be near one billion US dollars in United Kingdom [23, 24], Germany and France [25, 26].

Of the seven million people suffering of venous disease in USA nearly one million develop venous leg ulcers [27]. The average cost for one patient with venous leg ulcer is estimated to be $40.000 \$$ [27]. These data suggest the social and the economic importance of this disease and stress the importance of a good knowledge of the relationship between lymphatic and venous systems.

The aim of this study is to report the function of the lymphatic system of the lower limbs using qualitative and semiquantitative lymphoscintigraphy in: acute venous thrombosis, post-thrombotic syndrome with venous ulceration, postthrombotic syndrome without ulceration and control subjects.

\section{MATERIAL AND METHODS}

Patients data were collected from 1992 to 2000 at the Institute of Surgical Anatomy of the University of Genoa (San 
Martino Hospital, Genoa, Italy) and from 2000 to 2008 at the Department of General and Vascular surgery of Villa Scassi Hospital, Genoa, Italy. All the patients enclosed in the present study signed an informed consent.

\section{Patients}

Group a: thirteen patients (13 limbs, 3 men and 10 women; average age 45 year-old; range $27-68$ years) affected by acute venous thrombosis (echo-doppler diagnosis) in absence of malignancies.

Group b: Six healthy volunteers (12 limbs) free of lymphatic and venous pathology ( 2 men, 4 women; average age 41 year-old; range $24-65$ years).

Group c: eight patients with uncured chronic venous ulcerations (10 limbs because two had bilateral ulcerations) (6 men, 2 women; average age 62 year-old; range 44-76 years). These patients had chronic venous ulcerations for more than one year.

Group d: five patients with post-thrombotic syndrome that had a chronic venous ulceration that closed with medical, compressive and surgical therapies (6 limbs because one had bilateral ulcerations) ( 3 men, 2 women; average age 64 year-old; 51-76 years). All these patients underwent surgical ligature of incompetent veins (for example ligature of an incompetent great saphenous vein or of a perforant vein) and compressive theraphy. After 6-10 months from surgery the ulcers closed.

All the patients were studied by venous echo-doppler that revealed, in group a, the acute venous thrombosis and in groups $\mathrm{c}$ and $\mathrm{d}$ the venous insufficiency.

Using an insuline syringe, $0.1-0.2 \mathrm{ml}$ of tracer, corresponding to $20 \mathrm{M} \mathrm{Bq}$ of $(99 \mathrm{~m}) \mathrm{Tc}$ microcolloidal sulphire (Lymphoscint Solco ${ }^{\circledR}$ or Lymphoscint Nanocoll®) was injected in the first and third interdigital plicae in the subcutaneous tissue. Scintigraphic scans were taken at time zero and after 15, 30 and 60 minutes at the injection site and at the inguinal lymph nodes. Images are acquired using a gammacamera to great field (Elscint SPX or Siemens ECAM) with a collimator for low energies and high resolution (APS45HR) (matrix $128 \times 128$ ). The dynamic acquisition allows to see the lymphatics and the lymphonodes. During the first hour patients were kept at complete rest: TI 60 indicate the passive drainage of the lymph. The semi-quantitative evaluation of the lymphatic drainage is extablished by a numeric index (TI 60) calculated as: TI $60=\mathrm{K}+\mathrm{D}+0.04 \mathrm{~T}+\mathrm{N}+\mathrm{V}$. $\mathrm{K}$ is the lymphatic kinetics (no delay $=0$, low grade delay $=$ 3 , extreme delay $=5$, lack of transport $=9$ ); $\mathrm{D}$ is the distribution pattern of the tracer (normal $=0$, partial diffuse $=3$, diffuse $=5$, transport stop $=9$ ); $\mathrm{T}$ is the time expressed in minutes of tracer appearance in the inguinal lymph nodes (no appearance is 9), $\mathrm{N}$ is related to the number of inguinal lymph nodes seen at lymphoscintigraphy (no lymph nodes $=$ 9,1 lymph node $=5$, from 1 to 4 lymph nodes $=3$, more than 4 lymph nodes $=0) \mathrm{V}$ is the ratio between the visualization of lymph vessels and the visualization of lymph nodes (clearly demonstrated $=0$, faint visualization $=3$, hardly recognizable $=5$, no visualization $=9$ ). The patients were invited to walk normally after the first hour.

An abdominal scan was performed in patients with bilateral ulceration (two patients of group c) and in patients with post-thrombotic syndrome (group d) in order to study the liver uptake of the tracer.

Statistical analysis have been done using Kruscal-Wallis statistic for four groups, Mann-Whitney test with Bonferroni correction for non-parametric multiple comparisons of the TI 60 values.

\section{RESULTS}

Lymphoscintigraphy in group a patients shows constantly an acceleration of the drainage of the tracer from the interstitial space and an higher percentage of accumulation of the tracer in the inguinal lymph nodes respect to the contralateral limb (Figs. 1, 2).

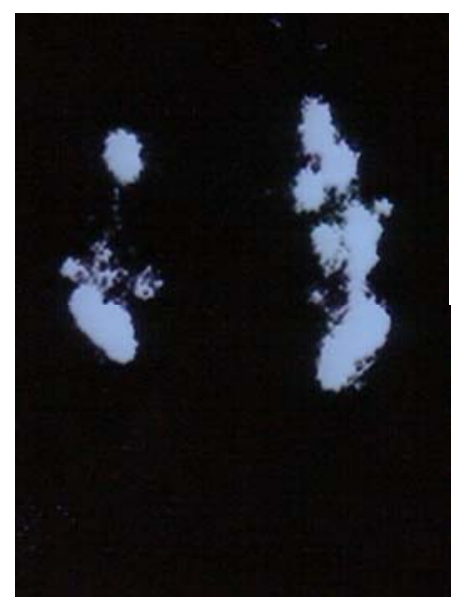

Fig. (1). Lymphoscintigraphy of inguinal lymph nodes after 60 minutes from the injection of the tracer in a patient with left deep acute venous thrombosis: increase of the uptake of the tracer in the inguinal lymph nodes of the affected limb respect to the contralateral one. In fact, in the left limb, there is a rapid transport of the tracer without extravascular diffusion, a fast appearance of the tracer in the inguinal lymph nodes with more than 4 visible lymph nodes and a clearly demonstration of lymphatic vessel, in early phases, and of lymph nodes, later.

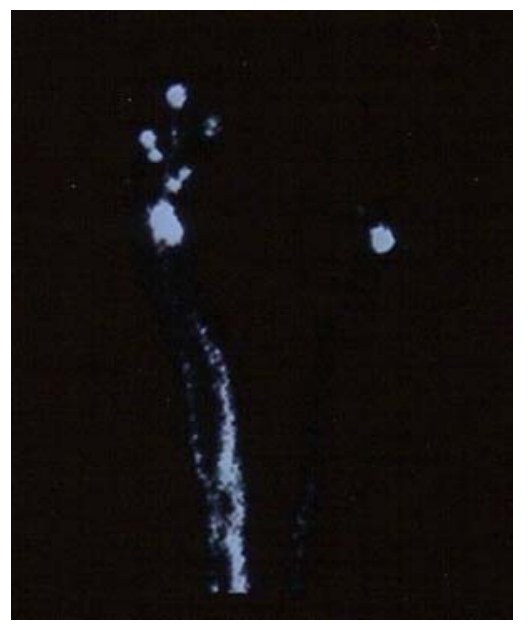

Fig. (2). Lymphoscintigraphy in a patient with right acute deep venous thrombosis: after 60 minutes from the injection of the tracer the captation is higher in the affected limb. Increase uptake of the tracer in the right inguinal lymphonodes respect to the contralateral.

Lymphoscintigraphy in group c patients with unilateral chronic venous ulcer reveals a delay of the drainage of the tracer from the interstitial space and a reduction of the accu- 
mulation of the marker in the inguinal lymph nodes respect to the heterolateral limb (Fig. 3). Patients with bilateral chronic venous ulceration have an important delay in the drainage of the tracer with the absence of the tracer in the liver after 2 hours (Fig. 4).

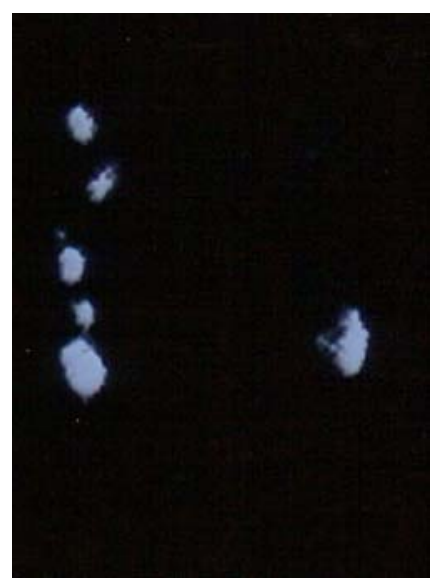

Fig. (3). Lymphoscintigraphy reveals a marked delay in the drainage of the tracer in the limb affected by chronic venous ulceration: reduction of the uptake of the tracer in the inguinal lymph nodes of the affected side. In fact, there is a extreme delay of the tracer with an extravascular diffusion; a faint visualization of the ratio between lymph nodes and lymphatics with a minor number of visible inguinal lymph nodes.

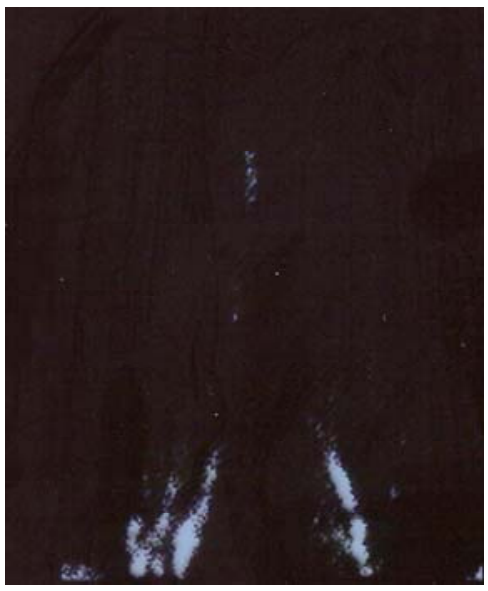

Fig. (4). Abdominal scan 2 hours after the injection of the tracer: in patients with bilateral chronic ulceration the tracer is not present in the liver.

Patients with post-thrombotic syndrome, after the closure of chronic venous ulceration (group d), have an improvement of the lymph flow. In the group d patient with bilateral ulcerations, after the healing of the ulcers, the tracer appear in the liver after 2 hours (Fig. 5).

The TI 60 is different among the four groups (TI 60 of group a is 398; TI 60 of group b is 203; TI 60 of group c is 114; TI 60 of group d is 148) (Kruskal-Wallis test; $\mathrm{D}=2048$, $45 ; \mathrm{H}=14,275$; this value exceeds the value 12,838 that defines the greatest $0.5 \%$ of values of the chi square distribution with $\mathrm{v}=\mathrm{k}-1=4-1=3$ degrees of freedom; $\mathrm{p} \leq 0.005$ ).

The Mann-Whitney test among group a and group $b$ (controls) reveals that difference for TI 60 is significant (smallest $\mathrm{T}=100 ; \mu \mathrm{t}=156 ; \alpha \mathrm{t}=18,384 ; \mathrm{z} \mathrm{t}=3,07 ; \mathrm{p} \leq 0.005$ ).

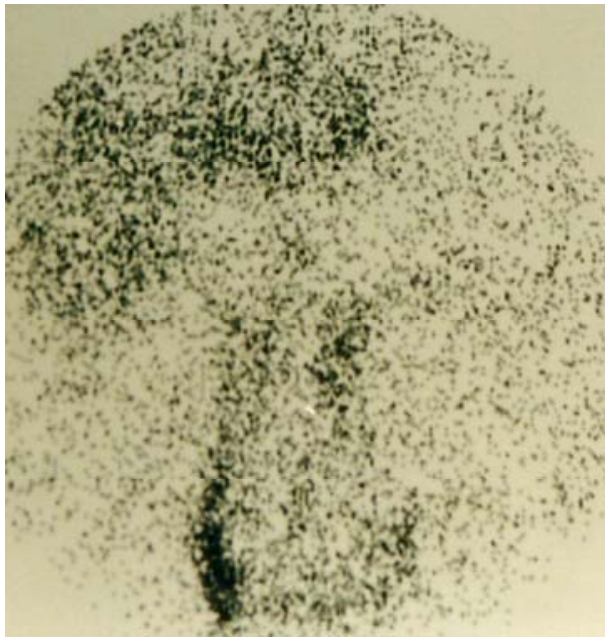

Fig. (5). Abdominal scan 2 hours after the injection of the tracer: presence of the tracer in the liver of patients with bilateral chronic venous insufficiency after the healing of the ulcerations.

Comparison of values of TI 60 between groups b (controls) and $\mathrm{c}$ shows significant differences (Mann-Whitney test; smallest $\mathrm{T}=29 ; \mu \mathrm{t}=57 ; \alpha \mathrm{t}=10,677 ; \mathrm{z} \mathrm{t}=2,75 ; \mathrm{p}$ $\leq 0.01$ ); also TI 60 values of group b (controls) and group d have significant differences (Mann-Whitney test; smallest T $=62 ; \mu \mathrm{t}=115 ; \alpha \mathrm{t}=14,832 ; \mathrm{z} \mathrm{t}=3,539 ; \mathrm{p} \leq 0.001)$. On the contrary, comparison of groups $\mathrm{c}$ and $\mathrm{d}$ has no significant differences (Mann-Whitney test; smallest $\mathrm{T}=65 ; \mu \mathrm{t}=51$; $\alpha \mathrm{t}$ $=9,219 ; \mathrm{z} \mathrm{t}=1,464 ; \mathrm{p}=\mathrm{ns})$. See Table $\mathbf{1}$.

\section{DISCUSSION}

The lymphatic system have always a compensatory function in acute venous thrombosis. Lymphoscintigraphy reveals that in the affected limb the lymphatic drainage of the interstitial space is increased respect to the controls. Moreover, also the percentage of tracer retained by inguinal lymph nodes (TI 60) is significantly higher in the affected limb.

Table 1. Results (Comparison of Groups with Mann-Whitney Test and Bonferroni Correction)

\begin{tabular}{|c|c|c|c|c|c|}
\hline & & Group A & Group B & Group C & Group D \\
\hline Group a & 398 & & $\mathrm{Zt}=3,07 ; \mathrm{p}<0,05$ & & \\
\hline Group b & 203 & $\mathrm{Zt}=3,07 ; \mathrm{p}<0,05$ & & $\mathrm{Zt}=2,75 ; \mathrm{p}<0,01$ & $\mathrm{Zt}=3,539 ; \mathrm{p}<0,001$ \\
\hline Group c & 114 & & $\mathrm{Zt}=2,75 ; \mathrm{p}<0.01$ & & $\mathrm{P}=\mathrm{ns}$ \\
\hline
\end{tabular}


These data definitively demonstrate that in acute venous thrombosis the lymphatic system drain more interstitial fluid in order to reduce the local edema. The incidence of postthrombotic syndrome is nearly $35 \%-69 \%$ at three years after deep venous thrombosis and from $49 \%$ to $100 \%$ after five to ten years [28-40].

Patients with chronic venous obstruction and venous reflux have the highest incidence of ulcerations [40]. When patients have been treated with adequate anticoagulation, mobilization and elastic compression, that enhance the lymphatic drainage, skin ulcerations are present in 4\%-8\% depending of the use of effective compressive therapy and local hygiene [41, 42]. These data suggest that a good compensatory function of the lymphatic system in deep venous thrombosis reduce local edema and prevent skin ulceration.

Patients with post-thrombotic syndrome and chronic venous ulcer have at lymphoscintigraphy a decreased lymphatic transport respect to controls. Morphologic studies have shown the collapse of lymphatics adjacent to venous ulcer [43]. At capillaroscopy, capillaries are dilated and associated with microedema and pericapillary fibrin [44]. Moreover, studies with electron microscopy reveals a marked reduction of the number of lymphatics in the ulcer, in para-ulcerous skin and several damages of the endothelial cells of lymphatics wall with the proliferation of microfilaments, the formation of vacuoles, the dilatation of mitochondria and the onset of the pinocytosis phenomenon [45]. These morphologic alterations of the endothelial cells indicate a cell suffering that impair the mechanisms of cell transport of ions, macromolecules and fluid. The smooth muscle cells in the wall of lymphatic collectors are damaged and shows vacuoles and destruction of myofibrils [45]. These alterations are the direct consequence of the venous hypertension and collaborate to the formation and the maintenance of venous ulceration. In fact, in patients with venous hypertension the white cells accumulate in vascular endothelium [46-48]. In absence of acute inflammation or infection the leucocytes pass into the interstitial space and are drained by lymphatics. In presence of a dermal infection or of a scratch lesion of the skin the lymphocytes are recalled in the interstitial space; the small lymphatics are plugged by lymphangitis and lymphangiothrombosis; the macromolecules that usually are drained by lymphatics "trap" the growth factors [49]; the lysosomial enzymes "digest" tissues and produces the ulceration.

Usually, in normal conditions the lymph flow of the leg goes from the superficial lymphatics to the subfascial lymphatics through out perforating lymphatic vessels [50]; in chronic venous ulcer the perforating lymphatic channels have an inverse flow (reflux) from the subfascial lymphatics to the epifascial ones [50]. The inadequate lymphatic drainage of the lipodermatosclerotic skin near the ulcer is responsible for local accumulation of fluid and catabolins. In previous studies we demonstrated that after the surgical and the compressive therapy of venous insufficiency and the local disinfection and cleaning of the ulcer there is an improvement of the lymph flow that is associated with the closure of the ulceration [51].

Patients with post-thrombotic syndrome without ulceration have a significantly reduced lymphatic drainage respect to controls but late abdominal scan with lymphoscintigraphy reveals a better drainage respect to patients with ulcerations (visualization of the liver after two hours) [51].

A recent review article on lymphoscintigraphy in chronic oedema [52] report different protocols for lymphoscintigraphy but it is restricted to the study of lymphedema patients and it don't consider patients with venous oedema, in particular there are not studies about the function of lymphatic system in patients with acute venous thrombosis, chronic venous ulcerations and in patients after the healing of the ulcers.

In conclusion, lymphatic system works together with venous system. It has a compensatory function in acute venous thrombosis. It has an important role in the formation and in the maintenance of chronic venous ulceration. Moreover recent studies $[53,54]$ indicate a crucial role of the vascular endothelial growth factor (VEGF)-C in the regulation of the expression of plated-derived growth factor (PDGF)-BB that is essential for capillary stabilization during angiogenic process [53]. Corneal inflammation is the most commonly used animal model to investigate lymphangiogenesis [54]. The source of VEGF-C comes from bone marrow CD11+ myeloid cell that are recruited to the inflamed corneal stroma. These results could be, in the next future, of clinical utility. In fact, interleukin-1 (IL-1) increases VEGF-C and VEGFR-mRNA in macrophages and the application of IL-1treated diabetes macrophages in diabetic mice induces lymphatic vessel formation and accelerated wound healing [54].

\section{REFERENCES}

[1] Harvey, W. Exercitatio anatomica de motu cordis et sanguinis in animalibus. Wilhelm Fitzer, Frankfurt/Main, 1628.

[2] Aselli, G. De Lactibus sine lacteis venis. Quarto Vasorum Mesaraicorum genere Novo invento Gasparis Asellii Cremonensis Anatomici Ticinensis Dissertatio. Qua sententiae Anatomicae multae, nel perperam receptae canuelluntur, nel parum perceptae illustrantur. AD Amplissimum et Excellissimum Regiu Senatu Mediolani, Apud Io: Baptam Bidellium. M.DC.XXVII, 1627.

[3] Cariati, A.; Pollinzi, V.; Cetta, F.; Cariati, P.; Conti, F.G.; Giua, R.; Cariati, E. Anatomy and drainage of chylous vessels: first and last studies. Lymphology, 2002, 35, 522-524.

[4] Butcher, H.R.; Hoover, A.L. Abnormalities of human superficial cutaneous lymphatics associated with stasis ulcers, lymphedema, scars and cutaneous autografts. Ann. Surg., 1955, 142, 633-653.

[5] Aukland, K.; Reed, R.K. Interstitial-lymphatic mechanism in the control of extracellular fluid volume. Physiol. Rev., 1993, 73, 1-78.

[6] Allegra, C. Microcirculatory techniques and assessment of chronic venous insufficiency. Medicographia, 1996, 18, 24-31.

[7] Stewart, G.; Gaunt, J.I.; Croft, D.N.; Browse, N.L. Isotope lymphography. A new method of investigating the role of the lymphatics in chronic limb oedema. Br. J. Surg., 1985, 72, 906-909.

[8] Bull, R.H.; Gane, J.N.; Evans, J.E.C.; Joseph, A.E.; Mortimer, P.S. Abnormal lymph drainage in patients with chronic venous leg ulcers. J. Am. Acad. Dermatol., 1993, 28, 585-590.

[9] Mortimer, P.S. Evaluation of lymphatic function: abnormal lymph drainage in venous disease. Int. Angiol., 1995, 14(3 Suppl. 1), 3235 .

[10] Rada, F.C.; Cristodor, P.; Rada, I.O. Lymphatic overload and venous diseases. Int. J. Angiol., 1994, 3, 70-76.

[11] Weddell, J.M. Varicose veins pilot study. Br. J. Prev. Soc. Med., 1966, 23, 179-186.

[12] Mekky, S.; Shilling, R.S.F.; Walford, J. Varicose vein in women cotton workers: an epidemiological study in England and Egypt. Br. Med. J., 1969, 2, 591-595.

[13] Coon, M.M.; Willis, P.W.; Keller, J.B. Venous thromboembolism and other venous disease in the Tecumseh Community Health Study. Circulation, 1973, 48, 839-846.

[14] Da Silva, A.; Widmer, L.K.; Martin, H.; Mall, T.; Glaus, L.; Schneider, M. Varicose veins and chronic venous insufficiency: 
prevalence and risk factors in 4376 subjects in the Basle Study II. Vasa., 1974, 3, 118-125.

[15] Beaglehole, R.; Prior, I.A.M.; Salmond, C.E.; Davidson, F. Varicose veins in the South Pacific. Int. J. Epidemiol., 1975, 4, 295299.

[16] Novo, S.; Avellone, G.; Pinto, A. Prevalence of primitive varicose veins of the lower limb in a randomized population sample of western Sicily. Int. Angiol., 1988, 7, 176-181.

[17] Stvrtinova, V.; Kolesar, J.; Wimmer, G. Prevalence of varicose veins of the lower limbs in the women working at a department store. Int. Angiol., 1991, 10, 2-5.

[18] Callam, M.J.; Ruckley, C.V.; Harper, D.R.; Dale, J.J. Chronic ulcerations of the leg: extent of the problem and provision of care. Br. Med. J., 1985, 290, 1855-1856.

[19] Nelzen, O.; Bergqvist, D.; Lindhagen, A. Leg ulcer etiology: a cross sectional population study. J. Vasc. Surg., 1991, 14, 557-564.

[20] Wille-Jørgensen, P.; Jørgensen, T.; Andersen, M.; Kirchoff, M. Postphlebitic syndrome and general surgery: an epidemiologic investigation. Angiology, 1991, 42, 397-403.

[21] Callam, M.J.; Harper, D.R.; Dale, J.J.; Ruckley, C.V. Chronic ulcer of the leg: clinical history. Br. Med. J., 1987, 294, 1389-1391.

[22] Hume, M. Presidential address: a venous renaissance? J. Vasc. Surg., 1992, 15, 947-951.

[23] Callam, M. Prevalence of chronic leg ulceration and severe chronic venous disease in Western Countries. Phlebology, 1992, 7 (suppl. $1), 6 s-12 s$.

[24] Jantet, G. Impact socio-économique de la pathologie veineuse en Grande Bretagne. Phlébologie, 1992, 45, 433-437.

[25] Laing, W. Chronic Venous Disease of the Leg. London, UK: Office of Health Economics; 1992, 1-44.

[26] Lafuma, A.; Fagnani, F.; Peltier-Pujol, F.; Rauss, A. La maladie veineuse en France: un probléme de santé publique méconnu. $J$. Mal. Vasc., 1994, 19, 185-189.

[27] Valencia, I.C.; Falabella, A.; Kirsner, R.S.; Eaglstein, W.H. Chronic venous insufficiency and venous leg ulceration. J. Am. Acad. Dermatol., 2001, 44, 401-21.

[28] Lindner, D.J.; Edwards, J.M.; Phinney, E.S.; Taylor, L.M.; Porter, J.M. Long-term hemodynamic and clinical sequelae of lower extremity deep venous thromboses. J. Vasc. Surg., 1986, 4, 436-442.

[29] Saarinen, J.; Sisto, T.; Laurikka, J.; Salenius, J.P.; Torkka, M. Late sequelae of acute deep venous thrombosis: evaluation five and ten years after. Phlebology, 1995, 10, 106-109.

[30] O'Donnell, TF.; Brose, N.L.; Burnand, K.G.; Thomas, M.L. The socioeconomic effects of an ilio femoral thrombosis. J. Surg. Res., 1977, 22, 483-488.

[31] Strandness, D.E.; Langlois, Y.; Cramer, M.; Randlett, A. Longterm sequelae of acute venous thrombosis. JAMA, 1983, 250, 12891292.

[32] Lindhagen, A.; Bergqvist, A.; Bergqvist, D.; Hallböök, T. Late venous function in the leg after deep venous thrombosis occurring in relation to pregnancy. Br. J. Obstet. Gynaecol., 1986, 93, 384352.

[33] Norris, C.S.; Darrow, J.M. Hemodynamic indicators of postthrombotic sequelae. Arch. Surg., 1986, 121, 765-768.

[34] Ákesson, H.; Brudin, L.; Dahlstrom, J.A.; Ekløf, B.; Ohlin, P.; Plate, G. Venous function assessed during a 5 year period after acute ilio-femoral venous thrombosis treated with anticoagulation. Eur. J. Vasc. Surg., 1990, 4, 43-48.

[35] Bergqvist, D. Prophylaxis against postoperative venous thromboembolism: a survey of surveys. Thromb. Haemorrh. Disord., 1990, 2, 69-73.

[36] Heldal, M.; Seem, E.; Sandset, P.M.; Abildgaard, V. Deep vein thrombosis: a 7-year follow-up study. J. Intern. Med., 1993, 234,
71-75.

[37] Milne, A.A.; Ruckley, C.V. The clinical course of patients following extensive deep vein thrombosis. Eur. J. Vasc. Surg., 1994, 8, 56-59.

[38] van Ramshorst, B.; van Bemmelen, P.S.; Hoeneveld, H.; Eikelboom, B.L. The development of valvular incompetence after deep vein thrombosis: a follow-up study with duplex scanning. J. Vasc. Surg., 1994, 19, 1059-1066.

[39] Labropoulos, N.; Leon, M.; Nicolaides, A.N.; Soreade, O.; Volteas, N.; Ortega, F.; Chan, P. Venous reflux in patients with previous deep venous thrombosis: correlation with ulceration and other symptoms. J. Vasc. Surg., 1994, 20, 20-26.

[40] Johnson, B.F.; Manzo, R.A.; Bergelin, R.O.; Strandness, D.E Relationship between changes in deep venous system and the development of the post-thrombotic syndrome after an acute episode of lower limb deep vein thrombosis: a one- to six-year follow-up. $J$. Vasc. Surg., 1995, 21, 307-313.

[41] Franzeck, U.K.; Schalch, I.; Jager, K.A.; Schneider, E.; Grimm, J.; Bollinger, A. Prospective 12-year follow-up study of clinical and hemodynamic sequelae after deep vein thrombosis in low-risk patients (Zurich Study). Circulation, 1996, 93, 74-79.

[42] Bradjes, D.P.M.; Büller, H.; Hejboer, H.; Huisman, M.V.; de Rijk, M.; ten Cate, J.W. Randomised trial of effect of compression stockings in patients with symptomatic proximal-vein thrombosis. Lancet, 1997, 349, 759-762.

[43] Poggi, P.; Marchetti, C.; Scelsi, R.; Cortinaris, R. Ultrastructure of dermal lymphatic vessels in chronic venous insufficiency of the human leg. Eur. J. Lymphol. Rel. Prob., 1993, 4 (No. 13), 19-23.

[44] Browse, N.L.; Burnand, K.G. The cause of venous ulceration. Lancet, 1982, 2, 243-245.

[45] Eliska, O.; Eliskova, M. Morphology in human venous crural ulcers with lipodermatosclerosis. Lymphology, 2001, 34, 111-123.

[46] Thomas, P.R.; Nash, G.B.; Dormandy, J.A. White cell accumulation in dependent legs of patients with venous hypertension: a possible mechanism for trophic changes in the skin. Br. Med. J., 1988, 296, 1693-5.

[47] Veraart, J.C.; Verhaegh, M.E.; Neumann, H.A.; Hulsmans, R.F.; Arends, J.W. Adhesion molecule expression in venous leg ulcers. Vasa., 1993, 22, 213-218.

[48] Shields, D.A.; Andaz, S.K.; Timothy-Antoine, C.A.; Scurr, J.H.; Porter, J.B. CD 11b/CD 18 as a marker of neutrophil adhesion in experimental ambulatory venous hypertension. Phlebology, 1995, 10 (Suppl. 1), 220-221.

[49] Falanga, V.; Eaglstein, W.H. The "trap" hypothesis of venous ulceration. Lancet, 1993, 341, 1006-8.

[50] Pietravallo, A.; Guzmán, A.; Cocozza, C. Relatioship between the insufficient perforating veins and the lymphatic system, in the subaponeurotic space from the internal side of the leg. Lymphology, 2002, 35, 587-592

[51] Cariati, A.; Giberto, M.; Pollinzi, V.; Cariati, P.; Traverso, E.; Cariati, S.; Cetta, F.; Giua, R.; Cariati, E. Instrumental evaluation in phlebolymphedemas. Lymphology, 2002, 35, 615-618.

[52] Vaughan, K. The use of lymphoscintigraphy in the management of chronic oedema. J. Lymphedema, 2006, 1, 42-57.

[53] Onimaru, M.; Yonemitsu, Y.; Fujii, T.; Tanii, M.; Nakano, T.; Nakagawa, K.; Kohno, R.; Hasegawa, M.; Nishikawa, S.; Sueishi, $\mathrm{K}$. VEGF-C regulates lymphangiogenesis and capillary stability by regulation of PDGF-B. Am. J. Physiol. Heart Circ. Physiol., 2009, 297, H1685-H1696.

[54] Xing, L.; Ji, R. Lymphangiogenesis, myeloid cells and inflammation. Expert. Rev. Clin. Immunol., 2008, 4, 599-613. 